\title{
A transradial percutaneous coronary intervention for complex lesions of the left main coronary artery and first obtuse marginal branch using a 7 French guiding catheter: a case report
}

\author{
Tomislav Krčmar*, \\ Ozren Vinter, \\ Nikola Kos, \\ Hrvoje Pintarić \\ 'University Hospital Centre \\ "Sestre milosrdnice", \\ Zagreb, Croatia \\ ${ }^{2}$ Magdalena Clinic for \\ Cardiovascular Medicine, \\ Krapinske Toplice, Croatia
}

RECEIVED:

February 9, 2016

ACCEPTED:

February 20, 2016

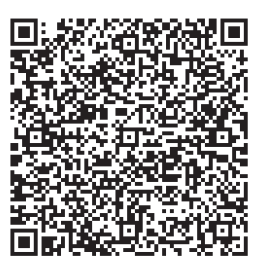

口 Cardiologia Croatica 2016;11(3-4):112.
KEYWORDS: left main coronary artery, intravascular ultrasound, culotte, transradial, drug-eluting stent. CITATION: Cardiol Croat. 2016;11(3-4):112. | DOI: http://dx.doi.org/10.15836/ccar2016.112

*ADDRESS FOR CORRESPONDENCE: Tomislav Krčmar, Klinički bolnički centar Sestre milosrdnice, Vinogradska 29, HR-10000 Zagreb, Croatia. / Phone: +385-99-520-0051 / E-mail: tomislav.krcmar@gmail.com

ORCID: Tomislav Krčmar, http://orcid.org/0000-0003-4689-1673 • Ozren Vinter, http://orcid.org/0000-0002-4236-7594 Nikola Kos, http://orcid.org/0000-0001-8829-2543 • Hrvoje Pintarić, http://orcid.org/0000-0002-7741-4194

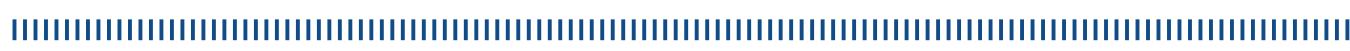

Transradial approach is well established and often used for percutaneous coronary intervention (PCI). The usual opinion is that transfemoral approach is preferable to transradial for complex PCI using a 7 French guiding catheter. ${ }^{1-3}$

We report a case of a 60-year-old male with a medical history of peripheral artery disease and stable angina who presented to the Emergency Department with phlegmon of the fourth digit on the left foot. The patient had significant cardiovascular risk factors including insulin-dependent type II diabetes mellitus, arterial hypertension and hyperlipidemia. Due to stable angina and presence of risk factors, coronary angiography was recommended. Coronary angiography revealed $70 \%$ stenosis of the distal left main artery that extended to the proximal circumflex and left anterior descending artery with first obtuse marginal artery also significantly narrowed. Coronary intervention was delayed because of the coexisting active phlegmon. Surgical revascularization was recommended but the patient refused surgical intervention (SYNTAX score 23). The patient was scheduled for an elective PCI the following month. The transradial PCI controlled by intravascular ultrasound (IVUS) was performed using a 7 French guiding catheter. Using the "culotte" technique, 2 drug-eluting stents were implanted in the left main coronary artery while additional stenting of the left anterior descending artery and the first obtuse marginal branch was performed with another two drug eluting stents. The total procedural radiation time was 25 minutes and $220 \mathrm{ml}$ of iodine contrast was used.

A complex PCI using a 7 French guiding catheter via transradial approach can be performed successfully and safely and it represents a good alternative to transfemoral approach in suitable patients.

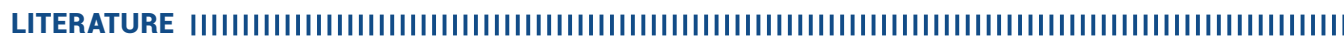

1. Sianos G, Morel MA, Kappetein AP, Morice MC, Colombo A, Dawkins K, et al. The SYNTAX score: an angiographic tool grading the complexity of coronary artery disease. EuroIntervention. 2005;1(2):219-27. PubMed: http://www.ncbi.nlm.nih.gov/pubmed/19758907

2. Egred M. Feasibility and safety of 7-Fr radial approach for complex PCI. J Interv Cardiol. 2011 0ct;24(5):383-8. DOI: http://dx.doi.org/10.1111/j.1540-8183.2011.00658.x

3. Wu CJ, Fang HY, Cheng Cl, Hussein H, Abdou SM, Youssef AA, et al. The safety and feasibility of bilateral radial approach in chronic total occlusion percutaneous coronary intervention. Int Heart J. 2011;52(3):131-8. DOI: http://dx.doi.org/10.1536/ihj.52.131 